\title{
İZOBÜTAN DEHİDROJENASYONU İÇİN Ca-Cr-MCM-41 KATALİZÖRLERİNİN SENTEZİ VE KARAKTERİZASYONU
}

\author{
Saliha ÇETINYYOKUŞ KILIÇARSLAN ${ }^{1}$, Meltem DOĞAN ${ }^{1 *}$, Timur DOĞU ${ }^{2}$ \\ ${ }^{1}$ Kimya Mühendisliği, Gazi Üniversitesi, 06570 Ankara, TÜRKIYE \\ ${ }^{2}$ Kimya Mühendisliği, Orta Doğu Teknik Üniversitesi, 06800 Ankara, TÜRKIYY \\ salihakilicarslan@gazi.edu.tr, meltem@gazi.edu.tr, tdogu@metu.edu.tr
}

(Geliş/Received: 20.01.2014; Kabul/Accepted: 06.06.2014)

\begin{abstract}
ÖZET
Yürütülen çalışmada, Cr-MCM-41 katalizörlerine Ca eklenmesinin, katalizör üzerindeki kromat türlerinin dağılımına ve katalizör aktifliğine etkileri araştırılmıştır. Çalışmada öncelikle farklı kalsiyum kaynakları $\left(\mathrm{CaCO}_{3}, \mathrm{CaCl}_{2}, \mathrm{Ca}\left(\mathrm{NO}_{3}\right)_{2}\right)$ kullanılarak emdirme yöntemi ile katalizörler sentezlenmiştir. İzobütan dehidrojenasyonunda en aktif kromat türü olarak bilinen monokromatlar, $\mathrm{CaCO}_{3}$ tuzu kullanılarak sentezlenen katalizörde belirlendiğinden çalışmanın ilerleyen bölümlerinde $\mathrm{CaCO}_{3}$ tuzu kullanılmıştır. Hidrotermal yöntemle sentezlenen katalizörlerde $\mathrm{Ca}$ emdirilmeden önce yapıda bulunan mono- ve di- kromat miktarlarında azda olsa bir artış gözlenmiştir. Emdirme tekniği ile sentezlenen katalizörlerde ise yapıda olmayan monokromat türlerinin $\mathrm{Ca}$ eklemeden sonra yapıda oluştuğu tespit edilmiştir. Farklı $\mathrm{Ca} / \mathrm{Cr}$ (kütle/kütle) oranlarında yürütülen çalışmalarda $\mathrm{Ca} / \mathrm{Cr}$ oranının 0,65 olduğu durumda, monokromatlar içindeki $\mathrm{O}-\mathrm{Cr}(\mathrm{VI})$ bağlarını gösteren pikin (380 nm) diğer katalizörlere göre daha şiddetli olduğu DR-UV-vis analizlerinden görülmüştür. Katalizör yüzey bileşimleri incelendiğinde en yüksek $\mathrm{Cr} / \mathrm{Si}$ oranı yine bu katalizörde belirlenmiştir. $\mathrm{Ca} / \mathrm{Cr}$ oranı 0,65 olacak şekilde emdirme ve hidrotermal sentez yöntemlerine göre sentezlenen katalizörlerin katalitik test çalışmaları 873K sıcaklık ve atmosferik basınçta gerçekleştirilmiştir. Bu testlerde yan reaksiyon ürünlerinin gözlenmemesi, katalizörleri izobüten seçiciliği yönünden ayrıcalıklı konuma getirmiştir. Emdirme ile sentezlenmiş katalizör yüzey alanında (Cr-MCM-41-EM) Ca ilavesi ile önemli bir azalış olmasına rağmen izobütan dönüşüm değerlerinin korunması, yapıda oluşan aktif monokromat türleri ile açıklanmıştır.
\end{abstract}

Anahtar kelimeler: İzobütan dehidrojenasyonu, Katalizör sentezi, Katalizör karakterizasyonu.

\section{SYNHTHESIS AND CHARACTERIZATION OF Ca-Cr-MCM-41 CATALYSTS FOR ISOBUTANE DEHYDROGENATION}

\begin{abstract}
In this study, the effects of $\mathrm{Ca}$ addition to $\mathrm{Cr}-\mathrm{MCM}-41$ catalysts on chromate species distribution over the catalyst and the catalyst activity were investigated. Firstly, catalysts were synthesized by impregnation method using different calcium sources $\left(\mathrm{CaCO}_{3}, \mathrm{CaCl}_{2}, \mathrm{Ca}\left(\mathrm{NO}_{3}\right)_{2}\right)$. Monochromates, were known as the most active chromate species for isobutane dehydrogenation, were determined on the synthesized catalysts using $\mathrm{CaCO}_{3} \mathrm{salt}$ so this salt was used in the forward studies. After Ca impregnation, a slight increase was observed in the amount of mono- and dichromate located in the structure of the catalysts synthesized by hydrothermal method. It was indicated that monochromate species absent before formed after $\mathrm{Ca}$ addition on the catalysts synthesized with impregnation technique. It was shown that in the case of $\mathrm{Ca} / \mathrm{Cr}$ ratio as 0.65 in the studies conducted at different $\mathrm{Ca} / \mathrm{Cr}$ (mass/mass) ratios, the peak (380nm) showing O-Cr (VI) bond in monochromate was more intense than the other catalysts from the DR-UV-vis analyzes. As regards the catalyst surface composition was examined, the highest $\mathrm{Cr} / \mathrm{Si}$ ratio was also determined in that catalyst. The catalytic test studies of the synthesized catalysts according to impregnating and hydrothermal synthesis methods at a $\mathrm{Ca} / \mathrm{Cr}$ ratio of 0.65 were performed at $873 \mathrm{~K}$ temperature and at atmospheric pressure. The catalysts become privileged position in terms of isobutene selectivity, because of the products of side reactions were not observed in these tests. Although a significant
\end{abstract}


decrease was seen on the surface area of the catalyst (Cr-MCM-41-EM) synthesized by impregnation method with the addition of $\mathrm{Ca}$, preservation of isobutane conversion values was explained by the active monochromate species formed in the structure.

Keywords: Isobutane dehydrogenation, Catalysts synthesis, Catalyst characterization.

\section{GÍRISS (INTRODUCTION)}

Motorlu araç performansını arttırmak üzere kullanılan benzin katkı maddelerinin başında bütil eterler gelmektedir. Bütil eterlerin kullanımındaki ihtiyaç, izobüteni kullanan yeni fabrikaların ve teknolojilerin gelişimine yol açmıştır. İzobüten, bütil eterler yanında butil kauçuk gibi kimyasalların üretiminde de hammadde olması yönüyle ilgi çekmektedir. Günümüzde ticari izobüten üretim prosesleri kısa katalizör ömrü, denge limitasyonu gibi problemler ile yürütülmektedir. İzobütan dehidrojenasyonu ile ilgili yapılan literatür araştırmasında reaksiyonun farklı katalizörler üzerinde yürütüldüğü belirlenmiştir. Nesterenko ve arkadaşları [1] yaptıkları çalışmada Ga ve Fe içeren MCM-41 destekli katalizörler üzerinde izobütan dehidrojenasyonunu incelemişlerdir. GaMCM-41 katalizörünün daha aktif olduğu gösterilmiştir. Emdirme tekniği ile sentezlenen $\mathrm{CrO}_{\mathrm{x}} / \mathrm{Al}_{2} \mathrm{O}_{3}$ katalizörleri ile yürütülen çalışmalarda $\mathrm{Cr}^{+6}$ 'nın indirgenmesi ile oluşan redoks $\mathrm{Cr}^{+3}$ oksitlerinin daha aktif olduğu gösterilmiştir [2,3]. Bu çalışmalarda katalizör deaktivasyonu redoks $\mathrm{Cr}^{+3}$ sitelerinin azalışı ile açıklanmıştır. Korhonen ve arkadaşları[4] tarafından da deaktivasyonun kromatların indirgenmesinden kaynaklandı $\breve{g}_{1}$ belirtilmiştir. Ding ve arkadaşları[5], aktif karbon destekli krom oksit katalizörü $\left(\mathrm{Cr}_{2} \mathrm{O}_{3} / \mathrm{AC}\right)$ üzerindeki çalışmalarında ortamda $\mathrm{CO}_{2}$ olması durumunda katalizör üzerinde kok birikiminin azaldığını göstermişlerdir. Fridman[6] tarafından yürütülen çalışmada $\mathrm{CrO}_{\mathrm{x}} / \mathrm{Al}_{2} \mathrm{O}_{3}$ katalizörü üzerinde ana reaksiyon dişında izobüten hidrojenasyon reaksiyonunun gerçekleştiği tespit edilmiştir. Kılıçarslan ve arkadaşları[7] yaptıkları çalışmada izobütan dehidrojenasyonu ve deaktivasyon mekanizmasını Cr-MCM-41 katalizörleri üzerinde incelemiştir. Kromat türleri içinde en aktif kromat türü olarak monokromatlar tespit edilmiş, katalizör deaktivasyonun tetrahedral koordinasyonlu $\mathrm{Cr}(\mathrm{VI}) \mathrm{O}_{4}$ türlerinin, oktahedral koordinasyonlu $\mathrm{Cr}(\mathrm{III}) \mathrm{O}_{6}$ ve $\mathrm{Cr}_{2} \mathrm{O}_{3}$ türlerine dönüşümüne bağlı meydana geldiği belirlenmiştir.

İzobütan dehidrojenasyonu ile ilgili son yıllardaki araştırmaların önemli bir kısmının katalizörlerin çeşitli elementler ile modifikasyonu ile aktifliğinin ve kararlılığının arttırılmasına yönelik çalışmalardan oluştuğu görülmektedir. $\mathrm{Fu}$ ve arkadaşları[8] tarafından $\mathrm{V}_{2} \mathrm{O}_{5} / \gamma-\mathrm{Al}_{2} \mathrm{O}_{3}$ üzerine $\mathrm{Sn}$ yüklendiğinde katalizörün aktivitesinde artış gözlenmiştir. Centeno ve arkadaşları[9], Pt-AlPON katalizöründe azot içeriğinin artması ile aktivitede artış tespit edilmiştir. Ohta ve arkadaşları[10] yaptıkları çalışmada Pt$\mathrm{Sn} / \mathrm{ZnO}-\mathrm{Cr}_{2} \mathrm{O}_{3}$ katalizöründe $\mathrm{Sn}$ ilavesi ile katalitik aktivitenin $\% 3$ Sn (ağırlıkça) içeriğine kadar yükseldiğini tespit edilmiştir. Serrano-Ruiz ve arkadaşları[11] tarafından $\mathrm{PtSn} / \mathrm{CeO}_{2}-\mathrm{C}$ katalizör olarak kullanılmıştır. Sn/Pt oranı 0,5 olduğunda en iyi izobüten verimi tespit edilmiştir. Jin ve arkadaşları[12] çalışmalarında alkali ve toprak alkali ( $\mathrm{Li}, \mathrm{Na}, \mathrm{K}$ ve $\mathrm{Ca})$ metallerin ilavesinin, $\mathrm{Mg}_{3}\left(\mathrm{VO}_{4}\right)_{2}$ katalizör yapısı ve fizikokimyasal özellikleri üzerine etkilerini incelemiştir. Krom temelli katalizörlerin modifikasyonu üzerine çalışmalar Pt kadar yoğun olmamakla birlikte alkali elementlerin eklenmesinin yapıda sentez sonrası istenen $\mathrm{Cr}^{+6}$ formlarının kararlılığını arttırdığ 1 ve aktif olmayan $\alpha-\mathrm{Cr}_{2} \mathrm{O}_{3}$ formunun oluşumunu engellediğini gösteren çalışmalar mevcuttur [13, 14, 15]. Dehidrojenasyon reaksiyonları için katalizör hazırlama çalışmalarında, yapıdaki metal formlarının sentez yönteminden önemli bir şekilde etkilediği gösterilmiştir [16].

Yürütülen çalışmada öncelikle farklı kalsiyum tuz kaynakları ile emdirme tekniğine göre Ca-Cr-MCM41 katalizörleri sentezlenmiştir. Seçilen metal tuz kaynağı ile $\mathrm{Ca} / \mathrm{Cr} \quad$ (kütle/kütle) $=0,65$ oranında hidrotermal olarak da katalizör sentezi gerçekleştirilmiştir. Kalsiyum eklemenin emdirme tekniği ile hazırlanan katalizörlerin yapısını önemli ölçüde etkilediği tespit edildikten sonra $\mathrm{Ca} / \mathrm{Cr}$ oranı 0,35 ve 0,85 alınarak da katalizörler sentezlenmiştir. Katalitik test çalışmaları $\mathrm{Ca} / \mathrm{Cr}$ oranı 0,65 olan katalizörler ile yürütülmüştür. Sentezlenen katalizörlerin reaksiyon öncesi ve sonrası karakterizasyon çalışmaları XRD, XPS, DR-UV-vis, $\mathrm{N}_{2}$ adsorpsiyon/desorpsiyon analizleri ile yürütülmüştür.

\section{DENEYSEL (EXPERIMENTAL)}

Sentezlenen katalizörlerin hazırlanmasında kullanılan metotlar ve yürütülen karakterizasyon çalışmalarına ait detaylı bilgiler bu bölümde sunulmuştur. Katalitik test çalışmalarında kullanılan sistem ve deneysel şartlar da bu bölümde verilmiştir.

2.1. Katalizör Sentezi ve Karakterizasyonu (Catalysts Synthesis and Characterization) 
$\mathrm{Bu}$ çalışmada, $\mathrm{Cr}$ aktif bileşenli MCM-41 katalizörlerinin farklı Ca metal tuz kaynakları $\left(\mathrm{CaCl}_{2}\right.$, $\left.\mathrm{CaCO}_{3}, \mathrm{Ca}\left(\mathrm{NO}_{3}\right)_{2}\right)$ ile modifikasyonu emdirme tekniğine göre yapılmıştır. Senteze öncelikle MCM41 destek maddesi sentezi ile başlanılmıştır. Saf MCM-41' in sentezinde silika kaynağı olarak sodyum silikat çözeltisi (\%27 ağ. $\mathrm{SiO}_{2}, \% 8$ ağ. $\mathrm{Na}_{2} \mathrm{O}, \% 65$ ağ. $\mathrm{H}_{2} \mathrm{O}$ ), yüzey aktif madde olarak N-setil-N,N,Ntrimetilamonyum bromit $\left(\mathrm{C}_{19} \mathrm{H}_{42} \mathrm{BrN}\right)$ kullanılmıştır. Sentez çalışmalarında yüzey aktif madde $/ \mathrm{Si}(\mathrm{mol} / \mathrm{mol})$ oranı 0,5 olarak seçilmiştir. Yüzey aktif madde, deiyonize su içerisine alınarak, $30^{\circ} \mathrm{C}$ 'de berraklaşıncaya kadar manyetik karıştırıcıda karıştırılmıştır. Ardından bu karışıma sodyum silikat çözeltisi damla damla ilave edilmiştir. Karışım, teflon-çelik bir otoklava alınmış ve $120^{\circ} \mathrm{C}$ ' de 4 gün etüvde bekletilmiştir. Etüvden alınan numune yıkama işlemine tabi tutulmuştur. Süzüntü pH'1 sabitlendiğinde $(\sim 7)$ yıkama işlemi sona erdirilmiştir. Oda sıcaklığında 1 gün kurumaya birakılan numune, cam bir reaktöre yerleştirilmiş ve $1^{\circ} \mathrm{C} / \mathrm{dk}$ 'lı sıcaklık artışı ile $600^{\circ} \mathrm{C}$ 'de 6 saat kuru hava akışında (135 $\mathrm{ml} / \mathrm{dk}$ ) kalsine edilmiştir. Farklı $\mathrm{Ca}$ metal tuz kaynakları üzerinden emdirme yöntemi ile katalizör sentezinde $\mathrm{Ca} / \mathrm{Cr}$ (kütle/kütle) oranı 0,65 olarak sabit tutulmuştur. MCM-41 numunesi deiyonize su içerisine alınmıştır. Deiyonize su-MCM-41 karışımının sıcaklığ $40^{\circ} \mathrm{C}$ ' ye ulaştığında, önce ilgili miktarda deiyonize suda çözünmüş krom nitrat tuzu çözeltisi karışıma eklenmiştir. $\mathrm{Bu}$ ekleme işlemi ardından deiyonize suda çözünmüş kalsiyum tuz kaynağ1 çözeltisi karışıma ilave edilmiştir. $\mathrm{CaCO}_{3}$ kullanıldığında çözme işleminde $\quad 4 \mathrm{~N} \quad \mathrm{H}_{2} \mathrm{SO}_{4}$ kullanılmıştır. İlave işlemi ardından sıcaklık $60^{\circ} \mathrm{C}^{\prime}$ ye yükseltilmiş ve buharlaştırma sağlanmıştır ( 2saat). Sentez sonrası elde edilen numune kazınarak bir saat camı üzerine alınmış, $100^{\circ} \mathrm{C}$ ' de 1 gün kurumaya bırakılmıştır. Son olarak numune bir kuvars cam reaktör içerisine alınarak $600^{\circ} \mathrm{C}^{\prime}$ de 6 saat $135 \mathrm{ml} / \mathrm{dk}$ kuru hava akıș hızında kalsine edilmiș ve katalizör sentezleri tamamlanmıștır. Emdirme tekniği ile $\mathrm{Ca} / \mathrm{Cr}$ (kütle/kütle) oranı 0,35 ve 0,85 olacak şekilde de katalizörler hazırlanmıştır. $\mathrm{Ca} / \mathrm{Cr}$ (kütle/kütle) oranı 0,65 alınarak hidrotermal sentez yöntemiyle $\mathrm{Ca}-\mathrm{Cr}$ MCM-41 katalizörleri sentezlenmiştir. MCM-41' in yukarıda anlatılan hidrotermal sentez prosedürüne göre, asitte çözünmüş $\mathrm{CaCO}_{3}$ ve deiyonize suda çözünmüş krom nitratın, silika kaynağı ile deiyonize su-yüzey aktif madde karışımına ilavesi sağlanmıştır. Yıkama ve kalsinasyon işlemleri MCM-41 sentezindeki aynı şartlarda gerçekleştirilerek katalizör (Ca-Cr-MCM-41-HT) elde edilmiştir.
Sentezlenen katalizörlerin karakterizasyonunda Xışını difraktometre (XRD, Rigaku Marka D/MAX 2200), $\mathrm{N}_{2}$ adsorpsiyon/desorpsiyon (Quantochrome, Autosorb-1), X-1şını foto elektron spektrometre (XPS, SPECS) ve Difüz reflaktans UV-vis. (DR-UV vis., Perkin Elmer RSA-PE-20) analizleri kullanılmıştır.

\subsection{Katalitik Test Çalışmaları (Catalytic Test Studies)}

Sentezlenen katalizörler, kuvars cam reaktöre $(\mathrm{L}=1 \mathrm{~m}$, $\mathrm{ID}=0,6 \mathrm{~cm}$ ) konularak bir tüp firın (Protherm Furnaces Model PTF 12/38/250) içerisine yerleştirilmiştir. Reaktörün ortasına gözenekli bir cam elek kaynatılmıştır. Tüm testlerde aynı miktarda katalizör $(0,1 \mathrm{~g})$, besleme akış yönünde reaktör içerisine yerleştirilmiştir. Saf izobütandan oluşan besleme, 20 ml/dk' lık akış hızında sisteme gönderilmiştir. İstenilen reaksiyon sıcaklığına ulaşıncaya kadar reaktör içinden azot akımı geçirilmiştir. Katalitik testler, $600^{\circ} \mathrm{C}$ sıcaklık ve atmosferik basınçta gerçekleştirilmiştir. Reaktör çıkışına yerleştirilen üç yollu vana ile numune alınacağı zaman akışın numune alma torbasına diğer zamanlarda da by-pass hattına gitmesi sağlanmıştır. Ürün analizi, gaz kromatografisi cihazında (GC SRI 8610C, silika kolon) gerçekleştirilmiştir.

\section{BULGULAR VE TARTIŞMALAR (RESULTS AND DISCUSSIONS)}

Yürütülen çalışmada elde edilen sonuçlar tartışmaları ile birlikte iki ana başlık altında bu bölümde sunulmuştur. Birinci bölümde katalizörlerin karakterizasyonuna ait sonuçlar, ikinci bölümde ise katalizörler ile yürütülen katalitik test çalışmalarına ait sonuçlar verilmiştir.

3.1. Hazırlanan Ca-Cr-MCM-41 Katalizörlerin Karakterizasyonu (Characterizations of the Prepared CaCr-MCM-41 Catalysts)

Sentezlenen MCM-41 desteği üzerine $\mathrm{Ca} / \mathrm{Cr}$ (kütle/kütle) oranı 0,65 olacak şekilde $\mathrm{Ca}$ ve $\mathrm{Cr}$ emdirilmiştir (Ca-Cr-MCM-41-EM). Çalışmanın başlangıcında kalsiyum kaynağı olarak üç farklı tuz kullanılmıştır $\left(\mathrm{CaCO}_{3}-\mathrm{K}, \mathrm{CaCl}_{2}-\mathrm{KL}\right.$ ve $\left.\mathrm{Ca}\left(\mathrm{NO}_{3}\right)_{2}-\mathrm{N}\right)$. Farklı kalsiyum kaynakları ile sentezlenen katalizörlerin DR-UV-vis analizlerine ait sonuçlar Şekil 1'de görülmektedir.

DR-UV-vis analizlerinde $320 \mathrm{~nm}$ civarında gözlemlenen pik dikromatlar içinde bulunan $\mathrm{O}-\mathrm{Cr}(\mathrm{VI})$ bağlarından kaynaklı yük transferine dayanmaktadır. $380 \mathrm{~nm}$ civarında gözlenen pikin monokromatlar içindeki O-Cr(VI) bağlarının yük transferinden kaynaklandığı literatürde belirtilmiştir [7]. $530 \mathrm{~nm}$ 


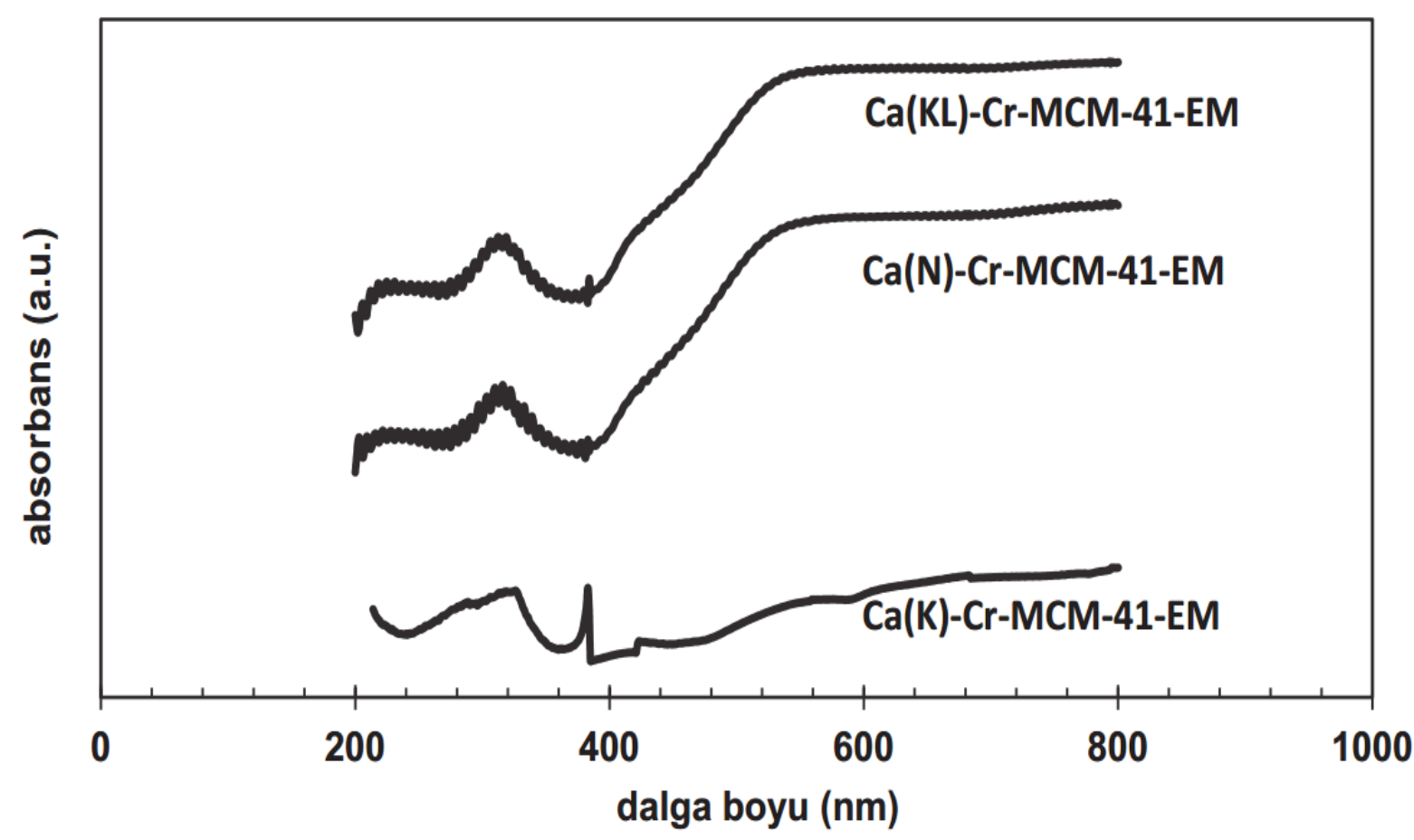

Şekil 1. Farklı kalsiyum tuzları ile sentezlenen katalizörlerin DR-UV-vis spektrumları $(\mathrm{Ca} / \mathrm{Cr}=0,65)(\mathrm{DR}-\mathrm{UV}$-vis spectrums of the synthesized catalysts with different calcium salts $(\mathrm{Ca} / \mathrm{Cr}=0.65))$

civarındaki dirsek oluşumları ise O-Cr(III) bağlarından kaynaklanmaktadır. Kılıçarslan ve arkadaşları tarafından yapılan çalışmada, katalizör yapısında bulunan monokromatların izobütan dehidrojenasyon reaksiyonunun aktivitesini olumlu yönde etkilediği gösterilmiştir [7]. Krom oksit katalizörlerinin dehidrojenasyon reaksiyonlarındaki aktivitesi doymamış $\mathrm{Cr}^{+3}$ türlerinden kaynaklanmaktadır. $\mathrm{Bu}$ doymamış $\mathrm{Cr}^{+3}$ türleri ise reaksiyon sırasında katalizörde başlangıçta bulunan $\mathrm{Cr}^{+6}$ formlarının indirgenmesi ile elde edilmektedir. Şekil 1 incelendiğinde monokromat oluşumu en fazla $\mathrm{CaCO}_{3}$ kullanılan katalizörde görülmektedir. $530 \mathrm{~nm}$ civarında beklenen ve dehidrojenasyon reaksiyonlarında aktif olmayan $\mathrm{Cr}$ (III)-O bağlarını gösteren dirseklerin $\mathrm{CaCl}_{2}$ ve $\mathrm{Ca}\left(\mathrm{NO}_{3}\right)_{2}$ tuzları kullanıldığında daha belirgin olduğu görülmektedir. Her üç tuz ile sentezlenen katalizörlerin Tek Nokta BET yüzey alanları içerisinde en yüksek yüzey alanı $121 \mathrm{~m}^{2} / \mathrm{g}$ olarak $\mathrm{CaCO}_{3}$ ile sentezlenen katalizörde belirlenirken en küçük yüzey alanı $57 \mathrm{~m}^{2} / \mathrm{g}$ olarak $\mathrm{CaCl}_{2}$ tuzu ile sentezlenen katalizörde tespit edilmiştir. Bu sonuçlara dayanarak çalışmanın ilerleyen bölümlerinde $\mathrm{Ca}$ yüklemesinin $\mathrm{CaCO}_{3}$ tuzu ile gerçekleştirilmesine karar verilmiştir. $\mathrm{Ca} / \mathrm{Cr}$ oranı 0,65 olacak şekilde $\mathrm{CaCO}_{3}$ tuzu kullanılarak hidrotermal yöntemle de CaCr-MCM-41-HT katalizörü sentezlenmiştir. Emdirme tekniği ve hidrotermal sentez yöntemleri ile sentezlenen katalizörlere ait DR-UV-vis analiz sonuçları, yapıda Ca eklemenin yarattığı farklılığın görülebilmesi amacıyla Ca eklenmemiş Cr-MCM-41 katalizörlerine ait sonuçlar ile birlikte Şekil 2'de verilmiştir.

Şekil 2' den hidrotermal sentez yöntemi ile sentezlenen katalizörde $\mathrm{Ca}$ eklenmeden önce de yapıda dikromatların $(320 \mathrm{~nm})$ ve monokromatların (380nm) bulunduğu görülmektedir. Kalsiyum eklenmesi ile mono- ve di- kromat miktarlarında azda olsa artış görülmektedir. Emdirme tekniğinde ise yapıya $\mathrm{Ca}$ eklenmesinin yapıda önemli değişiklere sebep olduğu görülmektedir. Yapıda Ca eklenmeden önce monokromatlar bulunmaz iken Ca eklenmesi ile monokromat türlerinin oluştuğu görülmektedir. Hidrotermal sentez yöntemi ile sentezlenen numunede ayrıca 220nm civarında görülen ve kromun destek ile yaptığı bağ1 gösteren pik kalsiyum emdirilen numunede görülmemektedir.

Hidrotermal sentez ve emdirme tekniği ile sentezlenen katalizörlerin Tek Nokta BET yüzey alanları ve gözenek hacimleri Tablo 1'de verilmiştir. Tablo 1 incelendiğinde beklendiği gibi her iki yöntem ile sentezlenen katalizörlerde kalsiyum yüklemesi sonucu yüzey alanı değerlerinde azalmalar görülmektedir. Emdirme tekniği ile sentezlenen katalizörde $\mathrm{Ca}$ yükleme sonrası yüzey alanı değerinin yaklaşı $\% 70$ oranında azaldığı görülürken hidrotermal sentez yönteminde \% 50’lik bir azalma gözlenmektedir. Emdirme ve hidrotermal sentez yöntemleri ile sentezlenen Ca-Cr-MCM-41 katalizörlerine ait XRD kırınım desenleri Şekil 3'de görülmektedir. 


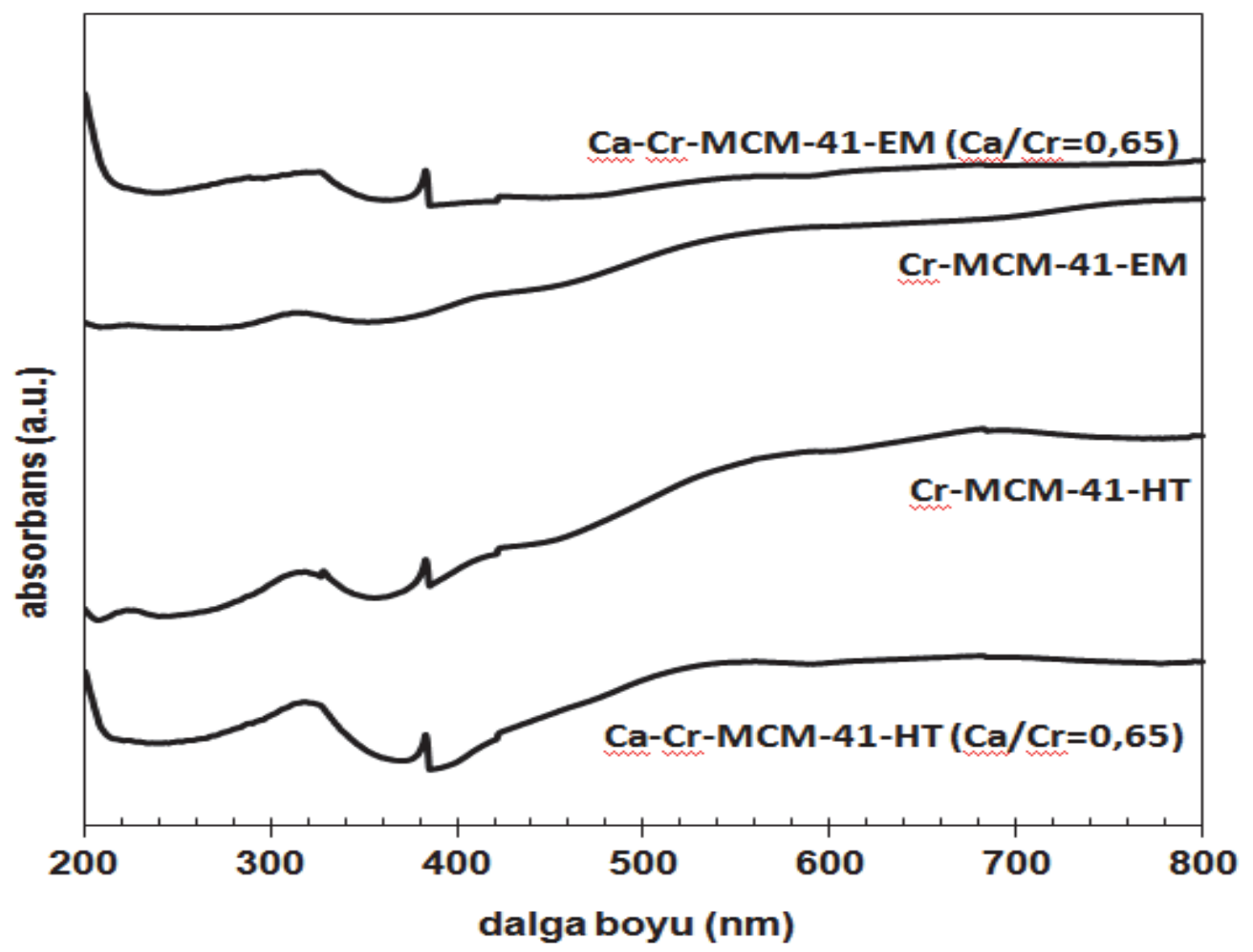

Şekil 2. Hidrotermal sentez ve emdirme tekniği ile sentezlenen katalizörlerin DR-UV-vis spektrumları (DR-UV-vis spectrums of the synthesized catalysts with hydrothermal synthesis and impregnation technique)

Tablo 1. Sentezlenen katalizörlerin Tek Nokta BET yüzey alanları ve gözenek hacimleri (Single Point BET surface areas and pore volumes of the synthesized catalysts)

\begin{tabular}{|l|c|c|}
\hline $\begin{array}{c}\text { Numune } \\
(\mathbf{C a} / \mathbf{C r}=\mathbf{0 , 6 5})\end{array}$ & $\begin{array}{c}\text { Tek Nokta BET yüzey } \\
\text { alanı }\left(\mathbf{m}^{\mathbf{2}} / \mathbf{g}\right)\end{array}$ & Gözenek hacmi (cc/g) \\
\hline $\mathrm{Cr}-\mathrm{MCM}-41-\mathrm{HT}$ & 990 & 0,761 \\
\hline $\mathrm{Ca}-\mathrm{Cr}-\mathrm{MCM}-41-\mathrm{HT}$ & 495 & 0,703 \\
\hline $\mathrm{Cr}-\mathrm{MCM}-41-\mathrm{EM}$ & 400 & 0,735 \\
\hline $\mathrm{Ca}-\mathrm{Cr}-\mathrm{MCM}-41-\mathrm{EM}$ & 121 & 0,420 \\
\hline
\end{tabular}

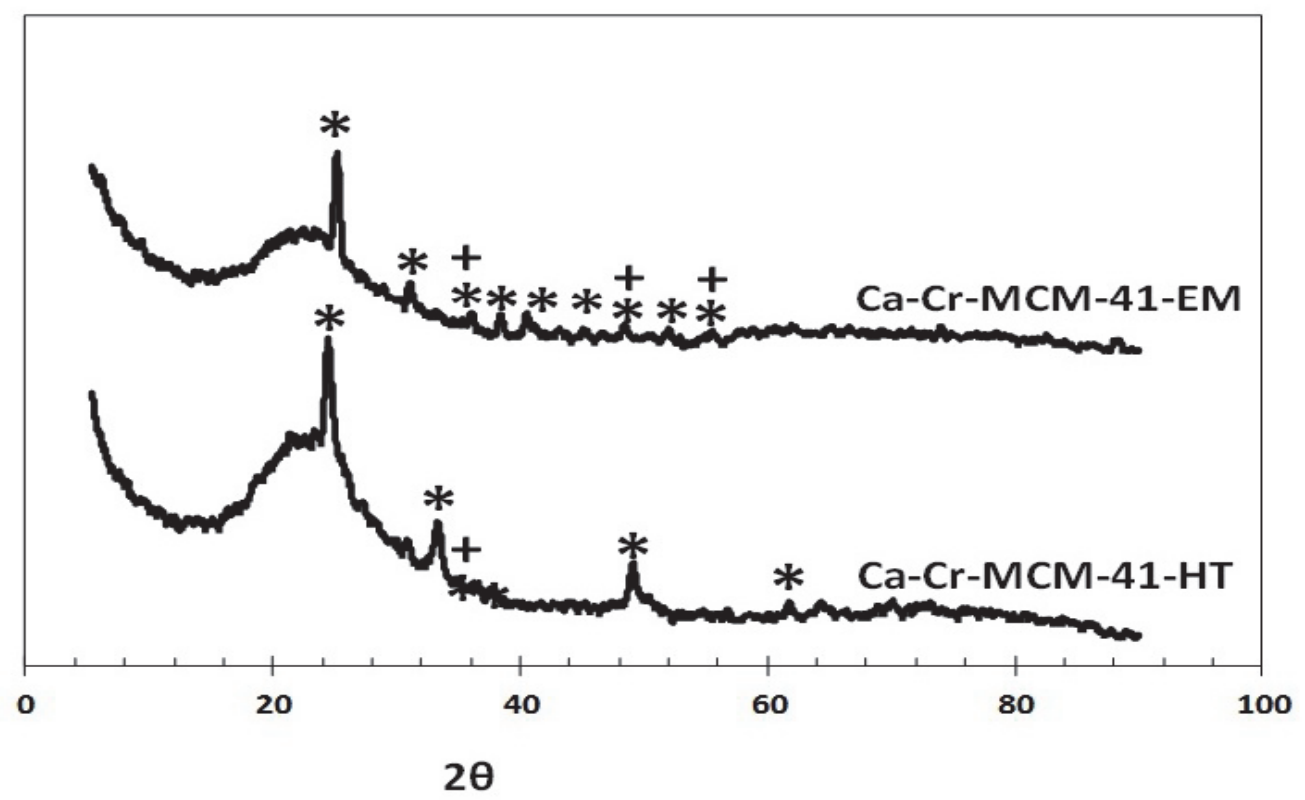

Şekil 3. Emdirme ve hidrotermal sentez yöntemleri ile sentezlenen katalizörlerin X-Işını kırınım desenleri $(\mathrm{Ca} / \mathrm{Cr}=0,65)\left(* \mathrm{CaCrO}_{4},+\alpha-\mathrm{Cr}_{2} \mathrm{O}_{3}\right)$ (X- Ray diffraction patterns of the synthesized catalysts with impregnation and hydrothermal synthesis) 
Katalizörlerin yapısında bulunan krom oksit formlarından ancak $\alpha-\mathrm{Cr}_{2} \mathrm{O}_{3}$ kristallerinin XRD analizi ile tespiti mümkündür $\left(34^{\circ}, 36^{\circ}, 50^{\circ}\right.$ ve $\left.55^{\circ}\right)$. Diğer oksit yapılar çok küçük kristal yapıda olduklarından tespit edilememektedir [14]. Şekil 4'den de görüldüğü gibi $\alpha-\mathrm{Cr}_{2} \mathrm{O}_{3}$ ve $\mathrm{CaCrO}_{4}$ kristallerini karakterize eden birçok pik çakışmaktadır. $\mathrm{CaCrO}_{4}$ yapısını karakterize eden piklerin hidrotermal sentez yöntemi ile hazırlanan katalizörde daha kuvvetli olduğu görülmektedir.

Yürütülen karakterizasyon çalışmaları, emdirme tekniğinde kalsiyum eklenmesinin oldukça etkili sonuçlar verdiğini göstermiştir. $\mathrm{Ca} / \mathrm{Cr}$ oranı 0,65 olacak şekilde yürütülen sentez çalışmaları yanında bu oran 0,35 ve 0,85 olacak şekilde de emdirme tekniği ile sentez çalışmaları yürütülmüştür. Farklı $\mathrm{Ca} / \mathrm{Cr}$ oranlarında sentezlenen katalizörlerin DR-UVvis analizlerine ait spektrumlar Şekil 4' de verilmiştir.

Şekil 4'den $\mathrm{Ca} / \mathrm{Cr}$ oranının artması ile $320 \mathrm{~nm}$ civarında görülen pikin parçalandığı görülmektedir. $\mathrm{Ca} / \mathrm{Cr}$ oranının 0,65 olduğu durumda, monokromatlar içindeki O-Cr(VI) bağlarını gösteren pikin (380 nm) diğerlerine göre azda olsa daha keskin olduğu görülmektedir. Farklı $\mathrm{Ca} / \mathrm{Cr}$ oranlarında sentezlenen katalizörlerin XPS analizleri ile yüzey bileşimi belirlenmiştir. Elde edilen sonuçlar Tablo 2'de verilmiştir. Yüzeyde tespit edilen C' ların kalsinasyon işlemi ile uzaklaştırılamayan organik bileşik kaynaklı olduğu düşünülmektedir. Tablo 2 'deki $\mathrm{Cr} / \mathrm{Si}$ oranları incelendiğinde en yüksek oran $\mathrm{Ca} / \mathrm{Cr}$ oranı 0,65 alınarak sentezlenen katalizörde görülmektedir.

\subsection{Katalitik Test Çalışmaları (Catalytic Test Studies)}

Emdirme tekniği ile hazırlanan katalizörler arasından $\mathrm{Ca} / \mathrm{Cr}$ oranı 0,65 olacak şekilde sentezlenen katalizör, yapısındaki monokromat türlerinin fazlalığı ve yüzeyde en fazla $\mathrm{Cr}$ miktarının tespit edildiği katalizör olması nedeniyle katalitik test çalışmaları için seçilmiştir. $\mathrm{Ca} / \mathrm{Cr}$ oranı 0,65 olacak şekilde, hidrotermal sentez yöntemi ile hazırlanan katalizör ile de katalitik test çalışmaları yürütülmüştür.

İzobütan reaksiyonunun yürütüldüğü reaktörlerde saf izobütan reaktant olarak kullanıldığında oluşması beklenen yan reaksiyonlar izobütanın parçalanma reaksiyonu ve hidrojenasyon reaksiyonudur. $\mathrm{Bu}$ çalışmada sentezlenen hiçbir katalizör üzerinde yan reaksiyon oluşmamış reaktör çıkışında ana reaksiyon ürünleri izobüten, hidrojen ve reaksiyona girmemiş izobütan tespit edilmiştir. $\mathrm{Bu}$ sonuç sentezlenen katalizörleri izobüten seçiciliği yönünden ayrıcalıklı bir konuma getirmektedir. Kütlece $\% 3 \mathrm{Cr}$ içeren hidrotermal sentez yöntemi ile sentezlenmiş $\mathrm{Cr}$ MCM-41-HT ve Ca-Cr-MCM-41-HT $(\mathrm{Ca} / \mathrm{Cr}=0,65)$ katalizörleri ile yürütülen katalitik testler sonucu reaksiyon süresince belirlenen izobütan dönüşümleri Şekil 5' de görülmektedir.

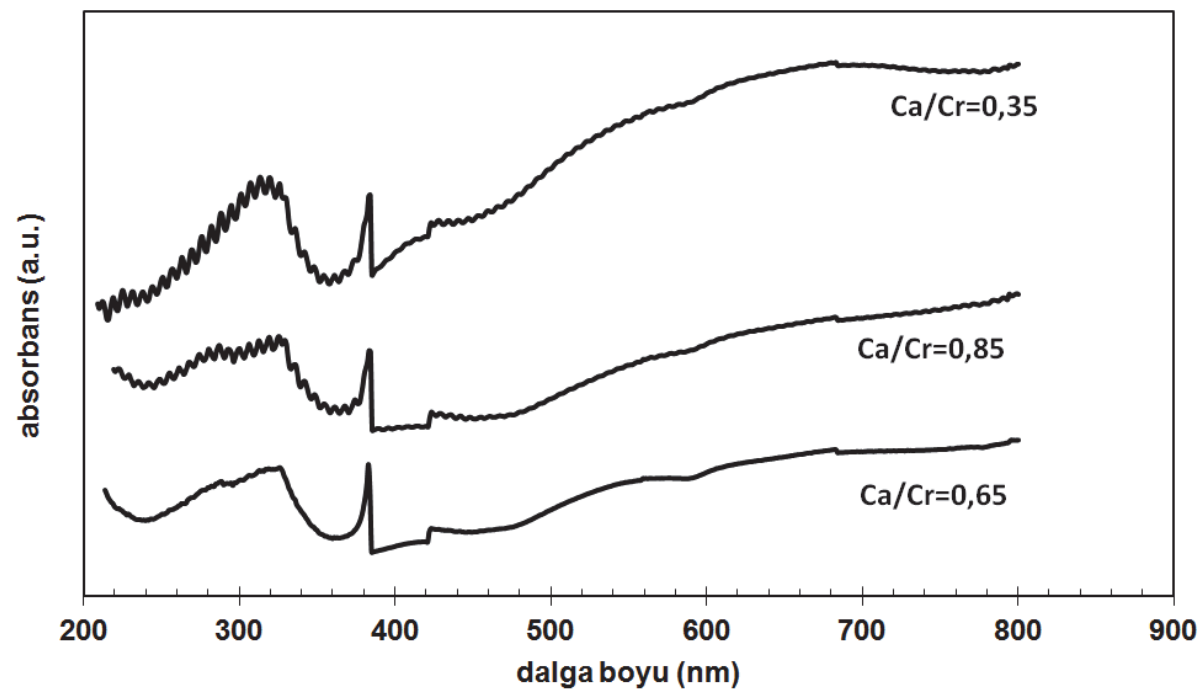

Şekil 4. Farklı Ca/Cr oranlarında emdirme tekniği ile hazırlanan katalizörlerin DR-UV-vis analiz sonuçları (DR$\mathrm{UV}$-vis results of the prepared catalysts with impregnation technique at different $\mathrm{Ca} / \mathrm{Cr}$ ratios)

Tablo 2. Farklı $\mathrm{Ca} / \mathrm{Cr}$ oranlarında emdirme tekniği ile sentezlenen katalizörlerinin yüzey bileşimleri (XPS analizleri) (Surface compositions (XPS Analaysis) of the synthesized catalysts with impregnation technique at different $\mathrm{Ca} / \mathrm{Cr}$ ratios)

\begin{tabular}{|c|c|c|c|c|c|c|}
\hline $\mathrm{Ca} / \mathrm{Cr}$ oran1 & $\mathrm{O}$ & $\mathrm{Si}$ & $\mathrm{C}$ & $\mathrm{Cr}$ & $\mathrm{Ca}$ & $\mathrm{Cr} / \mathrm{Si}$ oranı \\
\hline 0,35 & 67,5 & 25,1 & 6,0 & 0,8 & 0,6 & 0,032 \\
\hline 0,65 & 66,8 & 25,9 & 6,2 & 1,0 & 0,1 & 0,039 \\
\hline 0,85 & 68,0 & 24,9 & 5,9 & 0,9 & 0,3 & 0,036 \\
\hline
\end{tabular}




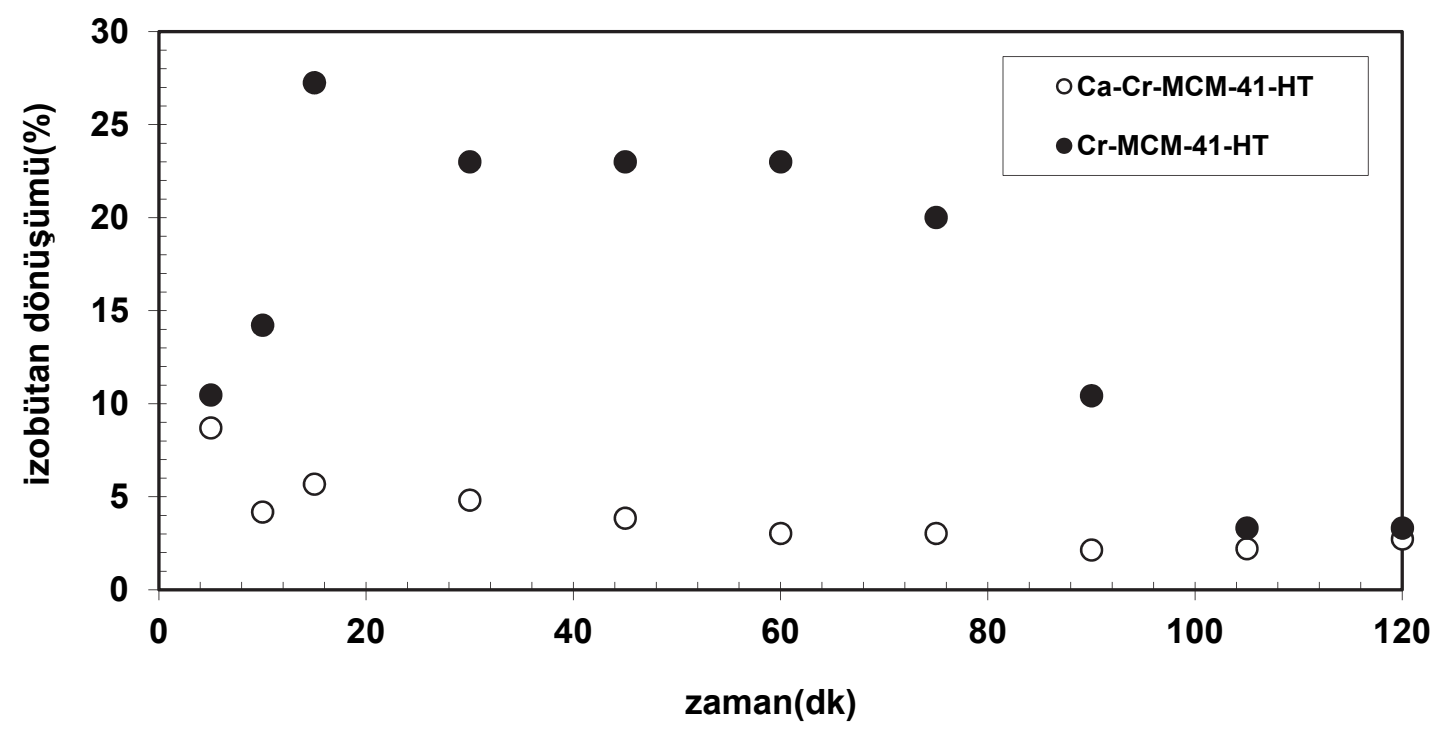

Şekil 5. Hidrotermal sentez yöntemi ile hazırlanan katalizörlere ait izobütan dönüşüm değerleri (reaksiyon sıcaklığ $1=600^{\circ} \mathrm{C}$, ortam basıncı $=$ atmosferik ) (Isobutane conversion values of the prepared catalysts with hydrothermal synthesis method (reaction temperature $=600^{\circ} \mathrm{C}$, pressure $=$ atmospheric))

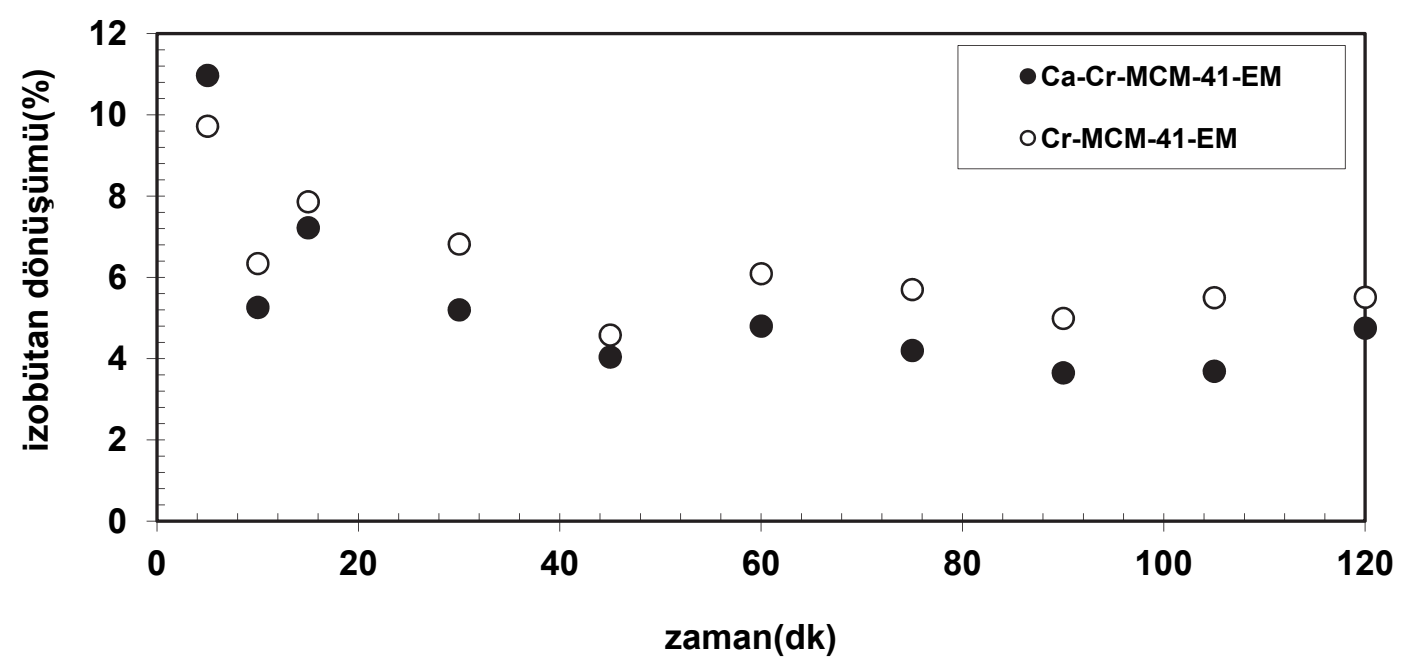

Şekil 6. Emdirme tekniği ile hazırlanan katalizörlere ait izobütan dönüşüm değerleri (reaksiyon sıcaklığ1 = $600^{\circ} \mathrm{C}$, ortam basinc1 $=$ atmosferik) (Isobutane conversion values of the prepared catalysts with impregnation technique (reaction temperature $=600^{\circ} \mathrm{C}$, pressure $=$ atmospheric))

Şekil 5'den görüldüğü gibi Ca-Cr-MCM-41-HT katalizörü üzerinde $\mathrm{Ca}$ eklenmemiş numuneye göre oldukça düşük dönüşüm değerleri elde edilmiştir. Bölüm 3.1'de belirtildiği gibi $\mathrm{Ca}$ eklenmesi hidrotermal sentez yönteminde azda olsa yapıda bulunan mono- ve di- kromat miktarlarında artışa neden olmuştu. XPS analizlerinde yüzeyde $\mathrm{Ca}$ yüklenmemiş katalizörlerde yüzeyde $\% 1,9$ oranında $\mathrm{Cr}$ gözlemlenirken $\mathrm{Ca}$ eklenmesi sonucu yüzeyde \% $0,9 \mathrm{Cr}$ belirlenmiştir. Dönüşüm değerlerindeki azalışın $\mathrm{Ca}$ ilavesinin aktif krom türlerini kapaması ve yüzey alanında meydana gelen azalmadan kaynaklanabileceği düşünülmektedir.

Emdirme tekniğine göre sentezlenen ağırlıç̧a \%3 $\mathrm{Cr}$ içeren Cr-MCM-41-EM ve Ca-Cr-MCM-41-EM $(\mathrm{Ca} / \mathrm{Cr}=0,65) \quad$ katalizörleri üzerinde belirlenen izobütan dönüşümleri ise Şekil 6'da verilmiştir. Her iki katalizör üzerinde elde edilen dönüşümlerin birbirinden çok farklı olmadığı Şekil 6'dan, görülmektedir. Bölüm 3.1 de belirtildiği gibi emdirme tekniği ile hazırlanan katalizörlerde $\mathrm{Ca}$ eklenmesi ile yüzey alanında \%70 civarında bir azalış 
meydana gelmiştir. Cr-MCM-41-EM katalizöründe bu azalışa karşılık yüksek sayılabilecek izobütan dönüşüm değerleri $\mathrm{Ca}$ emdirilmeden önce yapıda olmayan aktif monokromat türlerinin yapıda oluşması ile açıklanmıştır.

Reaksiyon uygulamalarında kullanılan katalizörlerin XPS analizleri ile belirlenen reaksiyon öncesi ve sonrası yüzey bileşimleri Tablo 3'de verilmiştir. Daha önceki bölümde de belirtildiği gibi sentezlenen katalizörlerde kalsinasyon işlemi sonrası uzaklaştırılamayan organik madde kaynaklı C tespit edilmiştir. Reaksiyon sonrası katalizörler yüzeyinde kok oluşumunun araştırılmasına yönelik oluşturulan Tablo 3 incelendiğinde hidrotermal sentez yöntemi ile sentezlenen katalizörde reaksiyon sonrası yüzeyde C birikiminin olmadığ 1 hatta azalma tespit edilmiştir. Emdirme tekniği ile sentezlenen katalizörlerde reaksiyon sonrası C miktarında \% 37' lik bir artış görülmektedir. XPS analizleri ile elde edilen C1s grafikleri de Tablo 3'de görülen durumu desteklemiştir.

Şekil 5 ve 6 incelendiğinde reaksiyon süresi ilerledikçe katalitik aktivitede düşüş gözlenmektedir. Özellikle hidrotermal sentez yöntemi ile sentezlenen katalizörlerde oldukça belirgin görülen aktivite azalmasının $\mathrm{C}$ oluşumuna bağlanamayacağı yukarıda yapılan tartışmalardan görülmektedir. $\mathrm{Bu}$ durumu açıklayabilmek için $\mathrm{Cr} 2 \mathrm{p}$ eğrileri (XPS analizlerinden) reaksiyon öncesi ve sonrası için oluşturulmuştur (Şekil 7).

Şekil 7 incelendiğinde, katalizörlerde $578 \mathrm{eV}^{\prime}$ da gözlenen kromatlar içindeki $\mathrm{Cr}^{+6}\left(2 \mathrm{p}_{3 / 2}\right)$ pikinin reaksiyon sonrasında kaybolduğu; $576 \mathrm{eV}^{\text {' da }}$ gözlenen $\mathrm{CrO}_{\mathrm{x}}$ veya $\mathrm{Cr}_{2} \mathrm{O}_{3}$ formu içindeki $\mathrm{Cr}^{+3}\left(2 \mathrm{p}_{3 / 2}\right)$ pikinin oluştuğu gözlenmiştir. Yine katalizörlerde $\mathrm{CrO}_{\mathrm{x}}$ veya $\mathrm{Cr}_{2} \mathrm{O}_{3}$ formu içindeki $\mathrm{Cr}^{+3}$ varlığını simgeleyen $586 \mathrm{eV}\left(2 \mathrm{p}_{1 / 2}\right)$ ' daki pik şiddetinin reaksiyon sonrasında arttığı gözlenmektedir. İzobütan dehidrojenasyonu için aktif $\mathrm{Cr}$ türü $\mathrm{Cr}^{+6}, \quad$ nın indirgenmesi ile oluşan doymamış $\mathrm{Cr}^{+3}$ türleridir. Buna göre, katalizörlerde reaksiyon süresince meydana gelen aktivite kaybının, $\mathrm{Cr}^{+6}$ formalarının $\mathrm{Cr}^{+3}$ formuna dönüşümünden kaynaklandığ 1 belirlenmiştir.

Tablo 3. Katalitik testler öncesi ve sonrası katalizörlerin yüzey bileşimleri (XPS analizleri) (Surface compositions of the catalysts before and after the catalytic tests)

\begin{tabular}{|c|c|c|c|c|c|c|c|c|c|c|}
\hline \multirow[t]{2}{*}{ Numune } & \multicolumn{5}{|c|}{ Reaksiyon öncesi } & \multicolumn{5}{|c|}{ Reaksiyon sonrası } \\
\hline & $\mathrm{O}$ & $\mathrm{Si}$ & $\mathrm{C}$ & $\mathrm{Cr}$ & $\mathrm{Ca}$ & $\mathrm{O}$ & $\mathrm{Si}$ & $\mathrm{C}$ & $\mathrm{Cr}$ & $\mathrm{Ca}$ \\
\hline Ca-Cr-MCM-41-HT & 66,4 & 25,5 & 6,8 & 0,9 & 0,4 & 68,4 & 25,3 & 4,9 & 0,8 & 0,6 \\
\hline Ca-Cr-MCM-41-EM & 66,8 & 25,9 & 6,2 & 1,0 & 0,1 & 65,4 & 24,9 & 8,5 & 0,9 & 0,4 \\
\hline
\end{tabular}

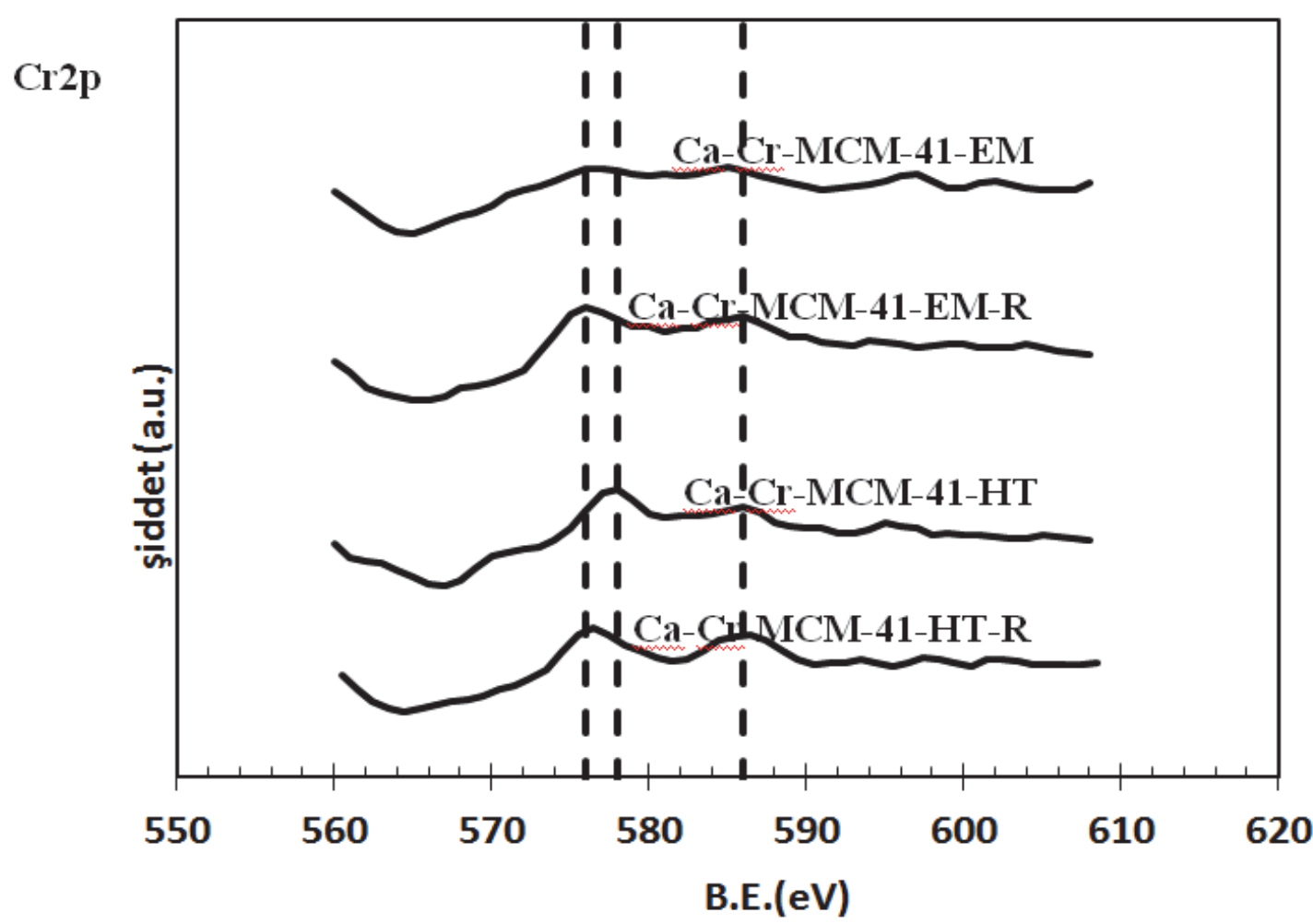

Şekil 7. Katalitik testler öncesi ve sonrası katalizörler için belirlenen Cr2p eğrileri (XPS analizleri) (Cr2p curves (XPS Analysis) for the catalysts before and after the catalytic tests) 


\section{SONUÇLAR (CONCLUSIONS)}

Yürütülen çalışmada Ca eklemenin Cr-MCM-41 katalizörlerinin yapısı ve izobütan dehidrojenasyonunda aktiviteye etkileri araştırılmıştır. Sentezde kalsiyum kaynağ 1 olarak $\mathrm{CaCO}_{3}$ kullanıldığında en fazla monokromat oluşumu tespit edilmiştir. Hidrotermal sentez yönteminde $\mathrm{Ca}$ eklenmeden önce de yapıda mono- ve di- kromatların yapıda bulunduğu, Ca eklenmesi ile her iki kromat türünde de azda olsa bir artış tespit edilmiştir. Emdirme tekniğinde $\mathrm{Ca}$ ekleme yapıda çok önemli değişikliklere sebep olmuştur. $\mathrm{Ca}$ eklenmeden önce yapıda monokromatlar görülmez iken $\mathrm{Ca}$ ekleme ile monokrotların oluşumu gözlenmiştir. $\mathrm{Ca} / \mathrm{Cr}$ oranının 0,65 olduğu durumda, monokromatlar içindeki OCr(VI) bağlarını gösteren pikin $(380 \mathrm{~nm})$ diğerlerine göre daha şiddetli olduğu görülmüştür. Yüzeyde en yüksek $\mathrm{Cr} / \mathrm{Si}$ oranı, $\mathrm{Ca} / \mathrm{Cr}$ oranı 0,65 alınarak sentezlenen katalizörde belirlenmiştir. Sentezlenen katalizörler üzerinde yürütülen katalitik testlerde hiçbir yan reaksiyon ürününü rastlanmamıştır. $\mathrm{Bu}$ durum, katalizörleri izobüten seçiciliği yönünden dikkat çekici konuma getirmiştir. Emdirme yöntemi ile sentezlenen katalizörde $\mathrm{Ca}$ ilavesi ile yüzey alanında ciddi azalışa rağmen yaklaşık aynı kalan izobütan dönüşüm değerleri, yapıda daha önce bulunmayan aktif monokromat türlerinin $\mathrm{Ca}$ eklenmesi ile oluşması ile açıklanmıştır. Katalitik aktivitedeki düşüşün, $\mathrm{Cr}^{+6}$ 'nın aktif olmayan $\mathrm{Cr}^{+3}$ formuna dönüşümünden kaynaklandığı gösterilmiştir.

\section{TEŞEKKÜR (ACKNOWLEGEMENTS)}

$\mathrm{Bu}$ çalışmamızı proje (Project No: 109M403) ve Yurtiçi Doktora Bursiyerlik programı ile destekleyen Türkiye Bilimsel ve Teknolojik Araştırma Kurumu' na teşekkür ederiz.

\section{KAYNAKLAR (REFERENCES)}

1. Nesterenko, N.S., Ponomoreva, O.A., Yuschenko, V.V., Ivanova, I.I. , Testa, F., Di Renzo, F. and Fajula ,F., "Dehydrogenation of ethylbenzene and isobutane over Ga- and Fe-containing mesoporous silicas", Applied Catalysis A: General, vol. 254, 261-272, 2003.

2. Weckhuysen, B.M., Verberckmoes, A.A., Debaere, J., Ooms, K., Langhans, I. and Schoonheydt, R.A., "In situ UV-Vis diffuse reflectance spectroscopy — on line activity measurements of supported chromium oxide catalysts: relating isobutane dehydrogenation activity with Cr-speciation via experimental design", Journal of Molecular Catalysis A: Chemical, vol. 151, 115-131, 2000.

3. Hakuli, A., Kytökivi, A. and Krause, A.O.I., "Dehydrogenation of i-butane on $\mathrm{CrO}_{\mathrm{x}} / \mathrm{Al}_{2} \mathrm{O}_{3}$ catalysts prepared by ALE and impregnation techniques", Applied Catalysis A: General, vol. 190, 219-232, 2000.

4. Korhonen, S.T., Airaksinen, S.M.K. and Krause, A.O.I., "In situ characterization of carbonaceous deposits formed on chromia/zirconia during isobutane dehydrogenation", Catalysis Today, vol. 112, 37-39, 2006.

5. Ding, J.F., Qin, Z.F., Li, X.K., Wang, G.F., Wang, J.G., "Coupling dehydrogenation of isobutane in the presence of carbon dioxide over chromium oxide supported on active carbon", Chinese Chemical Letters, vol. 19, 1059-1062, 2008.

6. Fridman, V.Z., "Pathways of light compounds formation during propane and isobutane dehydrogenation on Al-Cr catalysts “, Applied Catalysis A: General, vol. 382, 139-147, 2010.

7. Kilicarslan, S., Dogan, M. and Dogu, T., "Cr Incorporated MCM-41 Type Catalysts for Isobutane Dehydrogenation and Deactivation Mechanism", Ind. Eng. Chem. Res., vol. 52, 3674-3682, 2013.

8. Fu, Y., Ma, H., Wang, Z., Zhu, W., Wu, T. and Wang, G., "Characterization and reactivity of $\mathrm{SnO}_{2}$-doped $\mathrm{V}_{2} \mathrm{O}_{5} /-\mathrm{Al}_{2} \mathrm{O}_{3} \quad$ catalysts in dehydrogenation of isobutane to isobutene", Journal of Molecular Catalysis A: Chemical, vol. 221, 163-168, 2004.

9. Centeno, M.A., Debois, M. and Grange, P., "Platinum Aluminophosphate Oxynitride (PtAIPON) Catalysts for the Dehydrogenation of Isobutane to Isobutene", Journal of Catalysis, vol. 192, 296-306, 2000.

10. Ohta, M., Ikeda, Y. and Igarashi, A., "Preparation and characterization of $\mathrm{Pt} / \mathrm{ZnO}-\mathrm{Cr}_{2} \mathrm{O}_{3}$ catalyst for low-temperature dehydrogenation of isobutane", Applied Catalysis A: General, vol. 258, 153158, 2004.

11. Serrano-Ruiz, J.C., Sepúlveda-Escribano, A. and Rodríguez-Reinoso, F., "Bimetallic $\mathrm{PtSn} / \mathrm{C}$ catalysts promoted by ceria: Application in the nonoxidative dehydrogenation of isobutane", Journal of Catalysis, vol. 246, 158-165, 2007.

12. Jin, M., Lua, P., Yu, G.X., Cheng, Z.M., Chenc, L.F., Wang, J.A., "Effect of additives doping on catalytic properties of $\mathrm{Mg}_{3}\left(\mathrm{VO}_{4}\right)_{2}$ catalysts in oxidative dehydrogenation of cyclohexane", Catalysis Today, vol. 212, 142- 148, 2013.

13. Maldonado, F., Rivera, R. and Stashans, A., "Structure, electronic and magnetic properties of Ca-doped chromium oxide studied by the DFT method", Physica B, vol. 407, 1262-1267, 2012.

14. Neri, G., Pistone, A., De Rossi, S., Rombi, E., Milone, C. and Galvagno, S., "Ca-doped chromium oxide catalysts supported on alumina for the oxidative dehydrogenation of isobutane", Applied Catalysis A: General, vol. 260, 75-86, 2004.

15. David Raju, B., Rama Rao, K.S., Salvapathi, G.S., Sai Prasad, P.S. and Kanta Rao, P., "Influence of $\mathrm{K}_{2} \mathrm{O}$ addition on the aromatizationfunctionality of $\mathrm{Al}_{2} \mathrm{O}_{3}$-supported $\mathrm{Cr}_{2} \mathrm{O}_{3}$ catalysts in the transformation of isophorone", Applied Catalysis A: General, vol. 209, 335-344, 2001.

16. Yaşyerli, S., Aktaş, Ö., "MCF supported V-Mo$\mathrm{Nb}$ catalysts prepared by direct hydrothermal synthesis and impregnation methods for oxidative dehydrogenation of propane" Journal of The Faculty of Engineering and Architecture of Gazi University, vol. 27(1), 49-58, 2012. 
